\title{
MTHFR677T and 1298C Play Independent but Opposite Effects in Stroke - Additive Co-Effect of two Intragenic Alleles
}

\author{
Shuo $\mathrm{Li}^{1}$, Edward W Randell ${ }^{2}$, Fei-Yu Han ${ }^{2}$, Hong Zheng ${ }^{3}$, Liwen Zou ${ }^{4}$, Yuming Xu${ }^{1 *}$ and Ya-Gang Xie ${ }^{2,5 *}$ \\ ${ }^{1}$ Department of Neurology, First Affiliated Hospital of Zhengzhou University, Zhengzhou, Henan, PR China \\ ${ }^{2}$ Disciplines of Laboratory Medicine, Memorial University of Newfoundland, St. John's, NL, Canada \\ ${ }^{3}$ Department of Biology, Faculty of Medicine, Zhengzhou University, Zhengzhou, Henan, P. R. China \\ ${ }^{4}$ Department of Mathematics and statistics, University of New Brunswick, Saint John, NB, Canada \\ ${ }^{5}$ Department of Pathology, Faculty of Medicine, Dalhousie University, Halifax, NS, Canada \\ *Corresponding author: Ya-Gang Xie, Disciplines of Laboratory Medicine, Memorial University of Newfoundland, St. John's, NL, \\ Canada \\ Yumin Xu, Department of Neurology, First Affiliated Hospital of Zhengzhou University, Zhengzhou, Henan, PR China
}

\section{ARTICLE INFO}

Received: 幽 April 08, 2019

Published: April 17, 2019

Citation: Li S, Randell WE, Han F-Y, Zheng H, Zou L, Xu Y and Xie Y-G. MTHFR677T and 1298C Play Independent but Opposite Effects in Stroke - Additive Co-Effect of two Intragenic Alleles. Biomed J Sci \& Tech Res 17(1)2019. BJSTR. MS.ID.002954.

Keywords: MTHFR Gene Variants; Ischemic Stroke; Association; Additive Co-Effect of Intragenic Allele-Allele Interaction

Abbreviations: CVD: Cardiovascular Disease; IS: Ischemic Stroke; MTHFR: Methylenetetrahydrofolate Reductase; HWE: Hardy-Weinberg Equilibrium; RR: Risk Ratios

\begin{abstract}
Background and Purpose: The MTHFR677C>T variant has been repeatedly shown to associate with cardiovascular disease (CVD) including stroke. Discordant results have also been a frequent occurrence. Another prevalent intragenic variant, $1298 \mathrm{~A}>\mathrm{C}$, has frequently been shown not to be associated with CVD, including stroke, although much less studied compared with 677T. The relationship between $677 \mathrm{~T}$ and $1298 \mathrm{C}$ is unclear. Unidentified and variable genetic modifiers and environment factors in different populations could be the reason for inconsistent results from previous association studies. Studies designed using relatively ethnically homogenous populations can reduce heterogeneity in genetic background and environmental conditions. Use of a large sample size combined with the analysis of combined genotypes from two alleles could help determine independent effects of each variant (non-compound status) and co-effects of the two variants (compound status) if there are interactions.
\end{abstract}

Methods: Blood samples from 1429 ischemic stroke (IS) patients and 1171 healthy controls were collected from the North Han Chinese population. Genotyping of the 677C/T and 1298A/C were conducted using the Taq Man SNP genotyping technology on real-time PCR. Statistical analysis was performed focusing on the association between the combined genotypes from the two variants with IS.

\section{Results and Conclusions}

a) Both $677 \mathrm{~T}$ and $1298 \mathrm{C}$ have independent but opposite effects on IS when the two variants are not in compound status.

b) The 677T independently predisposes for IS, but susceptibility is only evident in homozygous status (dosage effect).

c) The $1298 \mathrm{C}$ is negatively associated with IS and is suggested to have an independent protective effect.

d) The two functional opposing effects of $677 \mathrm{~T}$ and $1298 \mathrm{C}$ have a neutralizing effect when the two variants are present in the compound status, which is evidence of an additive co-effect from the two intragenic alleles. The additive co-effect from the 677T and 1298C variants could be one explanation of previous association studies with MTHFR variants yielding discordant results. 


\section{Introduction}

Methylenetetrahydrofolate reductase (MTHFR) is essential for homocysteine metabolism [1] and elevated total homocysteine is associated with a variety of cardiovascular diseases (CVD) including stroke [2-9] although such associations may not be causal [9]. Two variants in the coding region of MTHFR gene, 677C $>\mathrm{T}$ (p. Ala222Val) and 1298A>C (p. Glu429Ala), are prevalent in North American, European and Asian populations, and the 677T is associated with elevations in total homocysteine levels [7-8,10-13]. For this reason, the 677T variant has been extensively investigated for association with CVD, including stroke, by using a variety of different populations [14-24], and including several meta-analyses [5,7-8, 25-27]. The association between $\mathrm{T}$ variant (especially homozygote of TT) and CVD, including stroke, was described in a large number of these studies [28-29] whereas, no association was seen in others, including a large meta-analysis [5,30-37]. Compared with the $677 \mathrm{~T}$ variant, the $1298 \mathrm{C}$ variant, located $2.1 \mathrm{~kb}$ from the 677T position, has not been extensively studied, and most studies published so far show no association with neither elevated homocysteine levels [13,38-39] nor CVD [10,18,24] and IS [7,40]. The relationship between the $677 \mathrm{~T}$ and $1298 \mathrm{C}$ variants remains a puzzle and continues to be the subject of much debate.

Etiologies of multifactorial disease usually involve multiple genetic events, environmental factors and the combination of both. For a single genetic variant with a strong effect, it is usually easy to demonstrate association with a related disease, and such association can easily be replicated in the different ethnic populations. However, a moderate or mild genetic effect modified by other genetic or environmental factors could present complicated results in association studies involving different ethnic populations due to differences in genetic background and environmental living conditions. A recent meta-analysis revealed a model of gene environment interaction in which the 677T effect on homocysteine levels was highly dependent on folate status [8]. The discordant results from previous association studies with $677 \mathrm{~T}$ indicates that the effect of the $677 \mathrm{~T}$ variant could be enhanced/diminished by other prevalent genetic change(s) acting either in concert or in opposition.

In the present study, the $677 \mathrm{~T}$ and $1298 \mathrm{C}$ variants were genotyped in 1429 ischemic stroke (IS) patients and 1171 healthy age and sex-matched controls from the North Han Chinese population. Considering the potential for interaction between the two intragenic variants, our study mainly focused on the association between IS and all genotypic combinations among the four different alleles of $677 \mathrm{C} / \mathrm{T}$ and $1298 \mathrm{~A} / \mathrm{C}$. The combined genotype analysis enabled us to determine the independent genetic effects of 677T and $1298 \mathrm{C}$ variants in the circumstance of non-compound status, as well as a possible co-effect of the two variants in a compound status.

\section{Methods}

\section{Studied Population:}

1,429 consecutives IS patients were recruited from 18 hospitals within Henan province during the period from February 2006 to March 2007. Clinical diagnosis of IS patients was based on the WHO criteria for IS (1998) plus evidence from MRI or CT exam suggestive of ischemic lesions corresponding to the neurological deficits. The 1,171 normal controls were selected from ethnically and geographically matched individuals without history of myocardial infarction or stroke who presented in hospitals for routine health examinations. Written informed consent was obtained from all patients. Ethics approval for this present study was granted by Committee of Ethics Boards of Zhengzhou University.

\section{Genotyping of $677 \mathrm{C}>\mathrm{T}$ (rs1801133) and 1298A $>C$ (rs1801131):}

Genomic DNA was isolated from peripheral blood using standard salt precipitation methods [41]. Genotyping of $677 \mathrm{C}>\mathrm{T}$ and $1298 \mathrm{~A}>\mathrm{C}$ were conducted using the Taq Man SNP genotyping technology on real-time PCR (ABI Prism $® 7000$ Sequence Detection System) which was described in our previous studies [42-43]. The primers and probes for $667>\mathrm{T}$ and were obtained from the validated TaqMan SNP genotyping kit supplied by Applied Biosystems (ABI; Foster City, CA).

\section{Prevalence determination and Statistical Analysis:}

The prevalence of each gene variant was calculated by counting the total carrier frequency including heterozygotes and homozygotes. Independent effect of each variant was determined by calculating the sum of prevalence for all possible combined genotypes. The allele frequencies were determined by gene counting. Tests of Hardy-Weinberg equilibrium (HWE) were carried out for all loci among Stroke patients and controls separately by the Chi-square test. Risk ratios (RR) were calculated as a measure of the relative risk for Stroke and were given with $95 \%$ confidence intervals. All statistical analyses were performed by using R 3.4.4 (R Core Team, Vienna Austria). Linkage disequilibrium between the $677 \mathrm{C}>\mathrm{T}$ and $1298 \mathrm{~A}>\mathrm{C}$ variants was calculated as D', which ranges from 0 (no linkage disequilibrium) to 1 or -1 (complete linkage disequilibrium).

\section{Results}

\section{General Genotyping Analysis}

The $677 \mathrm{C} / \mathrm{T}$ and $1298 \mathrm{~A} / \mathrm{C}$ variants were genotyped in the entire studied population including the 1492 IS patients and 1171 age and sex matched healthy controls from the North Han Chinese population. The genotype prevalence and allele frequency of each of $677 \mathrm{C} / \mathrm{T}$ and $1298 \mathrm{~A} / \mathrm{C}$ variants were analyzed individually. Details about the prevalence distributions of all possible genotypes from the two variants and the allele frequencies of the variants in patients and controls are given in Table 1 . The 677T variant presents the major allele with allele frequency of 0.5948 in the North Han Chinese population (control population). Without considering the fact of possible co-existence with 1298C variant allele, the $677 \mathrm{~T}$ variant was associated with IS by comparing the allele frequency ( $R R=1.0865,95 \%$ CI: 1.0407 1.1343, P=0.0002), and prevalence analysis of the sum of all genotypes with $\mathrm{T}$ allele $(\mathrm{CT}+\mathrm{TT})(\mathrm{RR}=1.0668,95 \% \mathrm{CI}: 1.0324-1.1024) \mathrm{P}=0.0001)$ between patients and controls. With respect to individual genotypes of $677 \mathrm{C} / \mathrm{T}$, the association was only observed for TT (RR=1.1308, 95\% CI: 1.0259-1.2464, $\mathrm{P}=0.0133$ ) but not for CT. This suggests that the $\mathrm{T}$ allele predisposes for IS, but the susceptibility becomes 
possible only with homozygous status (TT). Dosage effect of T allele was also suggested by comparing with the risk ratios (RR) generated from CT and TT analysis (1.0155 vs 1.1308) in patients and controls. On the contrary, the $1298 \mathrm{C}$ allele has a relatively low frequency (0.1337) in the North Han Chinese population (control population). The $\mathrm{C}$ allele, in general, was negatively associated with IS by comparing the allele frequency $(\mathrm{RR}=0.8456,95 \% \mathrm{CI}$ : 0.7311-0.9781, $\mathrm{P}=0.0239$ ) and the prevalence of all genotypes with
$\mathrm{C}$ alleles $(\mathrm{AC}+\mathrm{CC})(\mathrm{RR}=0.8448,95 \% \mathrm{CI}: 0.7333-0.9733, \mathrm{P}=0.0195)$ between the patients and controls. This suggests a protective effect of C allele against IS. Regarding each individual 1298A/C genotype, the negative association was only achieved in the genotype of AC ( $\mathrm{RR}=0.8438,95 \% \mathrm{CI}$ : 0.7271-0.9793, $\mathrm{P}=0.0254)$. The differences CC genotype frequency failed to achieve statistical significance, possibly due to the low prevalence of CC genotype in both patients and controls $(0.0161 \%$ vs $0.0188 \%)$.

Table 1: Genotype distributions and allele frequency in IS patient and normal control (NC) populations.

\begin{tabular}{|c|c|c|c|c|}
\hline Genotype & IS $(\mathrm{n}=1492)$ & $\mathrm{NC}(\mathrm{n}=1171)$ & RR ( $95 \% \mathrm{CI})$ & Pvalue \\
\hline \multicolumn{5}{|l|}{$677 \mathrm{C} / \mathrm{T}$} \\
\hline СТ & 0.464 & 0.4569 & $1.0155(0.9340,1.1042)$ & 0.7185 \\
\hline TT & 0.4143 & 0.3664 & $1.1308(1.0259,1.2464)$ & 0.0133 \\
\hline $\mathrm{CT}+\mathrm{TT}$ & 0.8782 & 0.8232 & $1.0668(1.0324,1.1024)$ & 0.0001 \\
\hline Tallele $F$ & 0.6463 & 0.5948 & $1.0865(1.0407,1.1343)$ & 0.0002 \\
\hline \multicolumn{5}{|l|}{$1298 \mathrm{~A} / \mathrm{C}$} \\
\hline $\mathrm{AC}$ & 0.1938 & 0.2297 & $0.8438(0.7271,0.9793)$ & 0.0254 \\
\hline $\mathrm{CC}$ & 0.0161 & 0.0188 & $0.8567(0.4800,1.5291)$ & 0.6008 \\
\hline $\mathrm{AC}+\mathrm{CC}$ & 0.2099 & 0.2485 & $0.8448(0.7333,0.9733)$ & 0.0195 \\
\hline Tallele $F$ & 0.113 & 0.1337 & $0.8456(0.7311,0.9781)$ & 0.0239 \\
\hline
\end{tabular}

Note: RR designates risk ratio

$\mathrm{CI}$ indicates confidence interval

\section{Combined Genotype Analysis}

The prevalence of combined genotypes among the each of the four alleles from $677 \mathrm{C} / \mathrm{T}$ and $1298 \mathrm{~A} / \mathrm{C}$ variants was investigated in patients and controls, and the results are depicted in Table 2. The combined genotypes of $677 \mathrm{CC} / 1298 \mathrm{AA}$, representing the homozygous wild type of both variants, was significantly higher in controls compared with IS patients. This supports the wild type status of both 677C and 1298A variants in the Chinese population. The combined genotypes, 677TT/1298AA and 677CC/1298CC denotes homozygous variants in one allele and homozygous wild type in the other allele. These two combined genotypes present ideal situations to determine independent effects of 677T and 1298C variants, respectively. The 677TT/1298AA genotype, but not the 677CT/1298AA genotype is significantly associated with IS ( $R R=1.3619,95 \% \mathrm{CI}: 1.2242-1.5151, \mathrm{P}=1.35 \mathrm{E}-08)$, which suggests that an independent effect of the $\mathrm{T}$ allele predispose to IS but the susceptibility only presents in the TT homozygous status (dosage effect). In term of the 1298C allele, the 1298AC/677CC genotype is negatively associated with IS (RR=0.6845, 95\% CI: 0.5043-0.9291, $\mathrm{P}=0.0150$ ), and suggests an independent protective effect for IS.

Table 2: Distributions of combined genotype and grouped combined genotypes in IS patient and normal control (NC) populations.

\begin{tabular}{|c|c|c|c|c|c|}
\hline $677 \mathrm{C} / \mathrm{T}$ & $1298 \mathrm{~A} / \mathrm{C}$ & IS $(n=1429)$ & $\mathrm{NC}(\mathrm{n}=1171)$ & RR ( $95 \% \mathrm{CI})$ & $P$ value \\
\hline \multirow{3}{*}{$\mathrm{CC}$} & AA & $80(0.0560)$ & $104(0.0888)$ & $\begin{array}{c}0.6304(0.4759 \\
0.8349)\end{array}$ & 0.0013 \\
\hline & $\mathrm{AC}$ & $71(0.0497)$ & $85(0.0726)$ & $\begin{array}{c}0.6845(0.5043 \\
0.9291)\end{array}$ & 0.015 \\
\hline & $\mathrm{CC}$ & $23(0.0161)$ & $18(0.0154)$ & $\begin{array}{c}1.0471(0.5678- \\
1.9308)\end{array}$ & 0.8829 \\
\hline \multirow{3}{*}{$\mathrm{CT}$} & $\mathrm{AA}$ & $459(0.3212)$ & $355(0.3032)$ & $\begin{array}{c}1.0595(0.9444 \\
1.1886)\end{array}$ & 0.3244 \\
\hline & $\mathrm{AC}$ & $204(0.1428)$ & $176(0.1503)$ & $\begin{array}{c}0.9498(0.7884 \\
1.1443)\end{array}$ & 0.588 \\
\hline & $\mathrm{CC}$ & $0(0.0000)$ & $4(0.0034)$ & NA & NA \\
\hline \multirow{3}{*}{$\mathrm{TT}$} & AA & $590(0.4129)$ & $421(0.3595)$ & $\begin{array}{c}1.3619(1.2242- \\
1.5151)\end{array}$ & $1.35 \mathrm{E}-08$ \\
\hline & $\mathrm{AC}$ & $2(0.0014)$ & $8(0.0068)$ & $\begin{array}{c}0.0093(0.0023- \\
0.0375)\end{array}$ & $4.51 \mathrm{E}-11$ \\
\hline & $\mathrm{CC}$ & $0(0.0000)$ & $0(0 \%)$ & NA & NA \\
\hline $677 \mathrm{~T}$ only & & & & & \\
\hline
\end{tabular}




\begin{tabular}{|c|c|c|c|c|}
\hline 677CT+TT/1298AA & $1049(0.7341)$ & $776(0.6627)$ & $\begin{array}{c}1.1077(1.0522, \\
1.1662)\end{array}$ & $9.60 \mathrm{E}-05$ \\
\hline \multicolumn{5}{|l|}{ 1298C only } \\
\hline 677CC /1298AC+CC & $94(0.0658)$ & $103(0.0880)$ & $\begin{array}{c}0.7479(0.5716 \\
0.9784)\end{array}$ & 0.0341 \\
\hline \multicolumn{5}{|l|}{$\begin{array}{l}\text { Genotypes of all } \mathrm{T} / \mathrm{C} \text { in } \\
\text { compound status }\end{array}$} \\
\hline $677 \mathrm{CT}+\mathrm{TT} / 1298 \mathrm{AC}+\mathrm{CC}$ & $206(0.1442)$ & $188(0.1605)$ & $\begin{array}{c}0.8979(0.7485 \\
1.0771)\end{array}$ & 0.2461 \\
\hline
\end{tabular}

Note: RR designates risk ratio

$\mathrm{CI}$ indicates confidence interval

The protective role of $1298 \mathrm{C}$ is effective in the heterozygote status. Unfortunately, examination of 677CC/1298CC genotype failed to demonstrate a negative association with IS, which may be due to the low prevalence of this genotype in patients $(0.0161)$ and controls (0.0154). Although the 677TT/1298AC genotype was associated with significant negative risk for IS (RR $=0.0093,95 \% \mathrm{CI}$ : 0.0023-0.0375, $\mathrm{P}=4.51 \mathrm{E}-11$ ), given the small number of subjects with this genotype caution must be exercised in the interpretation of this finding in the absence of confirmation. Moreover, there was no 677TT/1298CC nor 677CT/1298CC genotypes in the studied population. It was therefore not possible to examine for a co-effect involving $677 \mathrm{~T}$ and $1298 \mathrm{C}$ at this step of the analysis.

\section{Grouped Combing Genotypes Analysis}

A strategy of grouped combined genotype analysis was used to confirm the independent effects of $677 \mathrm{~T}$ and $1298 \mathrm{C}$ and investigate for a possible co-effect of both variants. The results of the association study with each grouped combined genotype are given in Table 2. In this study, the grouped genotypes 677CT+TT/1298AA represent all genotypes in which the $677 \mathrm{~T}$ is not in compound with 1298C. Similarly, the grouped combined genotypes of $677 C C / 1298 A C+C C$ represent all genotypes where the $1298 \mathrm{C}$ is not in compound with $677 \mathrm{~T}$. Finally, the grouped combined genotypes of $677 \mathrm{CT}+\mathrm{TT} / 1298 \mathrm{AC}+\mathrm{CC}$ represents all genotypes where $677 \mathrm{C}$ and $1298 \mathrm{~T}$ coexist (double homozygote, double heterozygote and homozygote heterozygote combination). Significant distribution disequilibrium of 677CT+TT/1298AA (RR=1.1077, 95\%CI: 1.0522 1.1662, $\mathrm{P}=9.60 \mathrm{E}-05)$ and $677 \mathrm{CC} / 1298 \mathrm{AC}+\mathrm{CC}(\mathrm{RR}=0.7479,95 \% \mathrm{CI}$ : 0.5716-0.9784, $\mathrm{P}=0.034$ ) were detected in patients compared with controls. This confirms an independent but functionally opposite effect of $677 \mathrm{~T}$ and $1298 \mathrm{C}$ for IS. Examination of all genotypes where the $677 \mathrm{~T}$ and $1298 \mathrm{C}$ alleles are found in compound status $(677 \mathrm{CT}+\mathrm{TT} / 1298 \mathrm{AC}+\mathrm{CC})$ showed that both the risk effect of $677 \mathrm{~T}$ and protective effect of $1298 \mathrm{C}$ were neutralized in patients compared with the controls when both variants are in compound status (RR 0.8979, 95\% CI: $0.7485-1.0771, \mathrm{P}=0.2461$ ). This is evidence of a genetic additive co-effect acting in opposite directions with respect to disease risk.

\section{Discussion}

Genetic predisposition in multifactorial disease, such as IS, results from a complicated co-effect from multiple genetic events. The multigenic effect can be due to either an additive co-effect from multiple independent genes, or synergistic co-effects from genegene and/or allele-allele interactions [44-45]. Most of the genetic susceptibilities described so far play a moderate or weak role in disease pathogeneses and the effects of susceptibilities are easily influenced by other genetic modifiers. Additive co-effects is result from the sum of all individual effects from multiple functioning independent genes, and a synergistic co-effect comes from two or more functioning related gene-gene interactions (genetic modifying). To demonstrate a co-effect from two or more genes, a large study population is necessary in order to gain sufficient statistical power for combined genotype distribution analysis. Furthermore, a population with less genetic heterogeneity is also critical because of sharing the similar genetic modifier(s). In this study, the 677C/T and 1298A/C were genotyped in 1492 IS patients and 1171 age and sex matched healthy controls from the North Han Chinese population. To ensure less heterogeneity in genetics and environment, all samples were collected from Henan Province and the majority of individuals originated from the local population.

The contradictory results concerning $677 \mathrm{~T}$ in previous association studies can be explained if there is co-existence of either genetic modifiers or another genetic event(s) with opposite effect. The susceptibility of 677T depends on prevalence of such coexistent genetic change(s) which could vary among different ethnic populations. The $677 \mathrm{~T}$ and $1298 \mathrm{C}$ genotypes are both located in the coding region of the MTHFR gene. Considering a possible intragenic allelic interaction, the two variants, in this study, were analyzed together focusing on the different combined genotypes among the four different alleles between the 677C/T and 1298A/C. High allelic frequencies of $677 \mathrm{~T}$ and $1298 \mathrm{C}$ and a relatively large sample size (2663) in the study gives sufficient statistical power to analyze the distribution of each combined genotype in patients and controls. Through an analysis of the combined genotyes where the two variants are not in compound status, we were able to determine the independent but opposite effects of $677 \mathrm{~T}$ and $1298 \mathrm{C}$ for IS. The independent effects of $677 \mathrm{~T}$ and $1298 \mathrm{C}$ were further confirmed by the grouped combined genotype study (677CT+TT/1298AA and $677 \mathrm{CC} / 1298 \mathrm{AC}+\mathrm{CC})$. Furthermore, the opposite effects of $677 \mathrm{~T}$ and $1298 \mathrm{C}$ were indirectly confirmed in the study with grouped combined genotype, $677 \mathrm{CT}+\mathrm{TT} / 1298 \mathrm{AC}+\mathrm{CC}$, which also suggests an additive co-effect from $677 \mathrm{~T}$ and 1298C. We, therefore, have reason to believe that discordant results in previous association studies with MTHFR may be the result of variable allele frequencies of $677 \mathrm{~T}$ and $1298 \mathrm{C}$ among the different studied populations. A 
continued effort to validate the findings from this study is under way.

Systemic inflammation has been reported as a major predisposing factor for CAD and stroke. Khalighi et al. [46] recently reported that the $677 \mathrm{~T}$ and $1298 \mathrm{C}$ have opposite effects on systemic inflammation where the 677T was significantly associated with increased NLR level and the1298C showed the opposite effects and tended to direct lower levels of NLR and PLR than 1298A. Our result provided evidence from a different angle to support independent but opposite effects of 677T and 1298C. Further study is needed to investigate the relationship between NLR level and IS and determine if the risk effect of $677 \mathrm{~T}$ and protective effect of $1298 \mathrm{C}$ for IS are mediated through a mechanism involving the pathogenesis of systemic inflammation.

Meta-analysis is a method that enables pooling data from smaller inconclusive studies to yield greater statistical power to allow one to quantify genetic risks more precisely. However, it is difficult for meta-analyses, in practice, to obtain data from all possible combined genotypes from the multiple studies based on the available published literatures. Moreover, variable gene frequencies among ethnically different populations could also be another challenge for meta-analyses to pin point a possible alleleallele/gene-gene interaction.

At present it is not possible to exclude $677 \mathrm{~T}$ and $1298 \mathrm{~A}$ being in linkage disequilibrium with other gene(s) associated with IS because these two variants are closely located in nucleotide position (same Linkage Disequilibrium block). However, such possibility is low considering the significantly higher prevalence of the combined genotype, 677CC/1298AA, in the control population $(\mathrm{RR}=0.6304 ; 95 \% \mathrm{CI}: 0.4759-0.8349, \mathrm{P}=0.0013)$. Furthermore, the independent protective effect of $1298 \mathrm{C}$ allele has been determined in this study. Although the sample size used in this study provides sufficient power to perform combined genotype analysis, a validation study with increased samples size is required and underway by our research group. The 677T was previously shown to affect folate metabolism and plasma homocysteine levels. The design of the present study did not permit a comparison of the genotypes with biochemical parameters. A study in this area to elucidate the relationship with biochemical risk factors would be of value in future research efforts.

\section{Conclusion}

The results of this study clearly demonstrate that

a) $677 \mathrm{~T}$ and $1298 \mathrm{C}$ play independent but opposite effects in IS when the two variants are not in compound status.

b) The $677 \mathrm{~T}$ independently predisposes for IS, but the IS susceptibility presents only in the homozygous status (dosage effect).

c) The $1298 \mathrm{C}$ is negatively associated with IS, and therefore plays a protective effect.

The two functionally opposite effects from the 677T and 1298C can be neutralizing when the two variants are in the compound status. This latter result also provides evidence of an additive coeffect for the two intragenic alleles.

\section{References}

1. Frosst P, Blom HJ, Milos R, Goyette P, Sheppard CA, et al. (1995) A candidate genetic risk factor for vascular disease: a common mutation in methylenetetrahydrofolate reductase. Nat Genet 10(1): 111-113.

2. Graham IM (1991) Homocysteine as a risk factor for cardiovascular disease. Trends Cardiovasc Med 1(6): 244-249.

3. Verhoef P, Kok FJ, Kruyssen DA, Schouten EG, Witteman JC, et al. (1997) Plasma total homocysteine, B vitamins, and risk of coronary atherosclerosis. Arterioscler Thromb Vasc Biol 17(5): 989-995.

4. Danesh J, Lewington S (1998) Plasma homocysteine and coronary heart disease: systematic review of published epidemiological studies. J Cardiovasc Risk 5(4): 229-232.

5. Wald DS, Law M, Morris JK (2002) Homocysteine and cardiovascular disease: evidence on causality from a meta-analysis. BMJ 325: 12021206.

6. Angeline T, Jeyaraj N, Tsongalis GJ (2007) MTHFR Gene polymorphisms, B-vitamins and hyperhomocystinemia in young and middle-aged acute myocardial infarction patients. Exp Mol Pathol 82(3): 227-233.

7. Yuan RY, Sheu JJ, Yu JM, Hu CJ, Tseng IJ, et al. (2009) Methylenetetrahydrofolate reductase polymorphisms and plasma homocysteine in levodopa-treated and non-treated Parkinson's disease patients. J Neurol Sci 287(1-2): 64-68.

8. Holmes MV, Newcombe P, Hubacek J, Sofat R, Ricketts SL, et al. (2011) Effect modification by population dietary folate on the association between MTHFR genotype, homocysteine, and stroke risk: a metaanalysis of genetic studies and randomised trials. Lancet 378(9791): 584-594.

9. Brattstrom L, Wilcken DE, Ohrvik J, Brudin L (1998) Common methylenetetrahydrofolate reductase gene mutation leads to hyperhomocysteinemia but not to vascular disease: the result of a metaanalysis. Circulation 98(23): 2520-2526.

10. Friedman G, Goldschmidt N, Friedlander Y, Ben Yehuda A, Selhub J, et al. (1999)A common mutation A1298Cin human methylenetetrahydrofolate reductase gene: association with plasma total homocysteine and folate concentrations. J Nutr 129(9): 1656-1661.

11. Laraqui A, Allami A, Carrié A, Raisonnier A, Coiffard AS, et al. (2007) Relation between plasma homocysteine, gene polymorphisms of homocysteine metabolism-related enzymes, and angiographically proven coronary artery disease. Eur J Intern Med 18(6): 474-483.

12. Ozbek Z, Kucukali CI, Ozkok E, Orhan N, Aydin M, et al. (2008) Effect of the methylenetetrahydrofolate reductase gene polymorphisms on homocysteine, folate and vitamin B12 in patients with bipolar disorder and relatives. Prog Neuropsychopharmacol Biol Psychiatry 32(5): 13311337.

13. Wang JC, Ouyang NY, Qu L, Lin TF, Zhang XL, et al. (2017) Effect of MTHFR A1298C and MTRR A66G genetic mutations on homocysteine levels in the Chinese population: a systematic review and meta-analysis. Journal of Translational Internal Medicine 5(4): 220-229.

14. Frosst P, Blom HJ, Milos R, Goyette P, Sheppard CA, et al. (1995) A candidate genetic risk factor for vascular disease: a common mutation in methylenete-trahydrofolate reductase. Nat Genet 10(1): 111-113.

15. Adams M, Smith PD, Martin D, Thompson JR, Lodwick D (1996) Genetic analysis of thermolabile methylenetetrahydrofolate reductase as a risk factor for myocardial infarction. QJM 89(6): 437-444.

16. Morita H, Taguchi J, Kurihara H, Kitaoka M, Kaneda H, et al. (1997) Genetic polymorphism of 5,10-methylenetetrahydrofolate reductase (MTHFR) as a risk factor for coronary artery disease. Circulation 95(8): 2032-2036. 
17. Jee SH, Beaty TH, Suh I, Yoon Y, Appel LJ (2000) The methylenetetrahydrofolate reductase gene is associated with increased cardiovascular risk in Japan, but not in other populations. Atherosclerosis 153(1): 161-168.

18. Abu Amero KK, Wyngaard CA, Al Boudari OM, Kambouris M, Dzimiri N (2003) Lack of association of lipoprotein lipase gene polymorphisms with coronary artery disease in the Saudi Arab population. Arch Pathol Lab Med 127(5): 597-600.

19. Almawi WY, Ameen G, Tamim H, Finan RR, Irani Hakime N (2004) Factor V G1691A, prothrombin G20210A, and methylenetetrahydrofolate reductase [MTHFR] C677T gene polymorphism in angiographically documented coronary artery disease. J Thromb Thrombolysis 17(3): 199-205.

20. Gallagher PM, Meleady R, Shields DC, Tan KS, Mc Master D, et al. (1996) Homocysteine and risk of premature coronary heart disease. Evidence for a common gene mutation. Circulation 94(9): 2154-2158.

21. Folsom AR, Nieto FJ, Mc Govern PG, Tsai MY, Malinow MR, et al. (1998) Prospective study of coronary heart disease incidence in relation to fasting total homocysteine, related genetic polymorphisms, and B vitamins: the Atherosclerosis Risk in Communities (ARIC) Study. Circulation 98(3): 204-210.

22. Schmitz C, Lindpaintner K, Verhoef P, Gaziano JM, Buring J (1996) Genetic polymorphism of methylenetetrahydrofolate reductase and myocardial infarction: a case-control study. Circulation 94: 1812-1814.

23. Mager A, Lalezari S, Shohat T, Birnbaum Y, Adler Y, et al. (1999) Methylenetetrahydrofolate reductase genotypes and early-onset coronary artery disease. Circulation 100(24): 2406-2410.

24. Kolling K, Ndrepepa G, Koch W, Braun S, Mehilli J, et al. (2004) Methylenetetrahydrofolate reductase gene C677T and A1298C polymorphisms, plasma homocysteine, folate, and vitamin B12 levels and the extent of coronary artery disease. Am J Cardiol 93(10): 12011206.

25. Klerk M, Verhoef P, Clarke R, Blom HJ, Kok FJ (2002) MTHFR Studies Collaboration Group. MTHFR 677C-->T polymorphism and risk of coronary heart disease: a meta-analysis. JAMA 288(16): 2023-2031.

26. Ray JG, Shmorgun D, Chan WS (2002) Common C677T polymorphism of the methylenetetrahydrofolate reductase gene and the risk of venous thromboembolism: meta-analysis of 31 studies. Pathophysiol Haemost Thromb 32(2): 51-58.

27. Lewis SJ, Ebrahim S, Davey Smith G (2005) Meta-analysis of MTHFR 677C->T polymorphism and coronary heart disease: does totality of evidence support causal role for homocysteine and preventive potential of folate? BMJ 331(7524): 1053-1057.

28. Beata Sarecka Hujar, Ilona Kopyta, Karolina Pienczk Reclawowicz, Daniel Reclawowicz, Ewa Emich-Widera (2012) The TT genotype of methylenetetrahydrofolate reductase $677 \mathrm{C}>\mathrm{T}$ polymorphism increases the susceptibility to pediatric ischemic stroke: meta-analysis of the 822 cases and 1,552 controls. Mol Biol Rep 39(8): 7957-7963.

29. Zhao M , Wang X , He M , Qin X , Tang G, et al. (2017) Homocysteine and Stroke Risk: Modifying Effect of Methylenetetrahydrofolate Reductase C677T Polymorphism and Folic Acid Intervention. Stroke 48(5): 11831190.

30. Wilcken DE, Wang XL, Sim AS, Mc Credie RM (1996) Distribution in healthy and coronary populations of the methylenetetrahydrofolate reductase (MTHFR) C677T mutation. Arterioscler Thromb Vasc Biol 16(7): 878-882.

31. Van Bockxmeer FM, Mamotte CD, Vasikaran SD, Taylor RR (1997) Methylenetetrahydrofolate reductase gene and coronary artery disease. Circulation 95: 21-23.

32. Ma J, Stampfer MJ, Hennekens CH, Frosst P, Selhub J, et al. (1996) Methylenetetrahydrofolate polymorphism, plasma folate, homocysteine, and risk of myocardias infarction in US physicians. Circulation 94(10): 2410-2416

33. Schwartz SM, Siscovick DS, Malinow MR, Rosendaal FR, Beverly RK, et al. (1997) Myocardial infarction in young women in relation to plasma total homocysteine, folate, and a common variant in the methylenetetrahydrofolate reductase gene. Circulation 96(2): 412-417.

34. Rothenbacher D, Fischer HG, Hoffmeister A, Hoffmann MM, März W, et al. (2002) Homocysteine and methylenetetrahydrofolate reductase genotype: association with risk of coronary heart disease and relation to inflammatory, hemostatic, and lipid parameters. Atherosclerosis 162(1): 193-200.

35. Zuntar I, Topić E, Vukosavić D, Vuković V, Demarin V, et al. (2003) Croatian population data for the C677T polymorphism in methylenetetrahydrofolate reductase: frequencies in healthy and atherosclerotic study groups. Clin Chim Acts 335(1-2): 95-100.

36. Kalina A, Czeizel AE (2004) The methylenetetrahydrofolate reductase gene polymorphism (C677T) is associated with increased cardiovascular mortality in Hungary. Int J Cardiol 97(2): 333-334.

37. Somarajan BI, Kalita J, Mittal B, Misra UK (2011) Evaluation of MTHFR C677T polymorphism in ischemic and hemorrhagic stroke patients. A case-control study in a Northern Indian population. J Neurol Sciences 304(1-2): 67-70.

38. Weisberg IS, Jacques PF, Selhub J, Bostom AG, Chen Z, et al. The 1298A-$>$ C polymorphism in methylenetetrahydrofolate reductase (MTHFR): in vitro expression and association with homocysteine. Atherosclerosis 156(2): 409-415.

39. Szczeklik A, Sanak M, Jankowski M, Dropinski J, Czachor R, et al. (2001) Mutation A1298C of methylenetetrahydrofolate reductase: risk for early coronary disease not associated with hyperhomocysteinemia. Am J Med Genet 101(1): 36-39.

40. Sarecka Hujar B , Kopyta I , Skrzypek M (2018) Is the 1298A>C polymorphism in the MTHFR gene a risk factor for arterial ischaemic stroke in children? The results of meta-analysis. Clin Exp Med 18(3): 337-345.

41. Miller SA, Dykes DD, Polesky HF (1988) A simple salting out procedure for extracting DNA from human nucleated cells. Nucleic Acids Res 16(3): 1215 .

42. Cui J, Randell E, Renouf J, Sun G, Green R (2006) Thrombospondin-4 $1186 \mathrm{G}>\mathrm{C}(\mathrm{A} 387 \mathrm{P})$ is a sex dependent risk factor for Myocardial infarction - a large replication study with increased sample size from the same population. American Heart Journal 152(3): 543.e1-5.

43. Li S, Xu Y M, Zheng H, Randell E, Wang H Z, et al. (2017) A Reduced Interval of Chromosome 9p21 Locus is Associated with Ischemic Stroke in Chinese Northern Han Population. International Journal of Genetics and Genomics 5(1): 14-18.

44. Butt C, Zheng H, Randell E, Robb D, Parfrey P, et al. (2003) Combined carrier status of prothrombin 20210A and factor XIII-A Leu34 alleles as a strong risk factor for myocardial infarction: evidence of a gene-gene interaction. Blood 101: 3037-3041.

45. Xie YG, Butt C, Randell E (2003) Gene-gene interactions in myocardial infarction. Blood 102: 1559-1560.

46. Khalighi K, Cheng G, Mirabbasi S, Khalighi B, Wu Y, et al. (2018) Opposite impact of Methylene tetrahydrofolate reductase C677T and Methylene tetrahydrofolate reductase A1298C gene polymorphisms on systemic inflammation. J Clin Lab Anal 32(5): e22401. 


\section{ISSN: 2574-1241}

DOI: 10.26717/BJSTR.2019.17.002954

Ya-Gang Xie, Yumin Xu. Biomed J Sci \& Tech Res

(c) (P) This work is licensed under Creative

Submission Link: https://biomedres.us/submit-manuscript.php

$\begin{array}{ll}\text { BIOMEDICAL } & \text { Assets of Publishing with us } \\ \text { RESEARCHES } & \text { Global archiving of articles } \\ & \text { - Immediate, unrestricted online access } \\ \end{array}$

